Article

\title{
Evaluation of natural and factitious food sources for Pronematus ubiquitus on tomato plants
}

\author{
Marcus V. A. Duarte ${ }^{1 *}$, Dominiek Vangansbeke ${ }^{2}$, Juliette Pijnakker ${ }^{3}$, Alfredo Benavente ${ }^{4}$, Rob Moerkens ${ }^{5}$, Yves \\ Arijs $^{6}$, Ana Lizbeth Flores Saucedo ${ }^{7} \&$ Felix Wäckers ${ }^{8}$ \\ Biobest Group N.V., Westerlo, Belgium; Marcus.Duarte@biobestgroup.com \\ 2 Biobest Group N.V., Westerlo, Belgium; Dominiek.vangansbeke@biobestgroup.com \\ 3 Biobest Group N.V., Westerlo, Belgium; juliette.pijnakker@biobestgroup.com \\ 4 Biobest Group N.V., Westerlo, Belgium; Alfredo.Benavente@biobestgroup.com \\ 5 Biobest Group N.V., Westerlo, Belgium; Rob.Moerkens@biobestgroup.com \\ 6 Biobest Group N.V., Westerlo, Belgium; Yves.Arijs@biobestgroup.com \\ 7 Georg-August-University Goettingen, Molecular Phytopathology and Mycotoxin Research, Goettingen, \\ Germany; anaflores.0591@gmail.com \\ 8 Biobest Group N.V., Westerlo, Belgium; Felix.Wackers@biobestgroup.com
}

Simple Summary: Biocontrol practitioners have been increasingly releasing generalist predators to combat a variety of greenhouse pests. In this study, we compared two lines of the generalist predatory mite Pronematus ubiquitus and the ability to explore a variety of alternative food sources that this mite could encounter on the tomato crop.

Abstract: Pronematus ubiquitus (McGregor) is a small iolinid mite that is capable of establishing on tomato plants. Once established, this mite has been shown to control both tomato russet mite, Aculops lycopersici (Tryon) (Acari: Eriophyidae) and tomato powdery mildew (Oidium neolycopersici L. Kiss). In the present study, we explored the nutritional value of various food sources in the laboratory. First, we assessed the reproduction of two food sources that P. ubiquitus can encounter on a tomato crop: tomato pollen and powdery mildew. In a second laboratory experiment, we evaluated the nutritional value of two types of prey mites: the astigmatid Carpoglyphus lactis L. (Acari: Carpoglyphidae) and the tarsonemid Tarsonemus fusarii (Acari: Tarsonemidae). Powdery mildew and C. lactis did not contribute to the reproduction, whereas tomato pollen and T. fusarii did allow egglaying. However, Typha angustifolia pollen was a superior food source in both experiments. In a greenhouse trial on individual caged tomato plants, we evaluated the impact of pollen supplementation frequency on establishment of $P$. ubiquitus. Here, a pollen addition frequency of every other week was required to allow populations of $P$. ubiquitus to establish.

Keywords: Biological control, alternative food, Tydeidae

\section{Introduction}

In contrast to the long-held conviction that specialist natural enemies are required to guarantee effective pest control [1], biocontrol practitioners have been increasingly releasing generalist predators to combat a variety of greenhouse pests [2,3]. Generalist predators possess several interesting properties, explaining this shift: (1) generalist predators feed on several pest species. A single generalist predator species thus affects populations

.

0
1
2
3
4
5
6
5


of multiple pest species simultaneously [4,5]. (2) They are more likely to be able to exploit alternative food sources, such as pollen, fungi or plant sap [6,7] which may enable them to build-up populations in the absence of prey food [9-12]. (3) generalist predators are generally easier and cheaper to mass-produce [13]. For example, phytoseiid predatory mites can be mass-produced on factitious astigmatid prey mites [14,15]. As a result, generalist phytoseiid predatory mites such as Amblyseius swirskii (Athias-Henriot), Neoseiulus californicus (McGregor) and Neoseiulus cucumeris (Oudemans), are now among the most important arthropod biocontrol agents worldwide [16,17] and are introduced in a wide range of crops, mostly in protected cultivation. In protected crops like pepper and cucumber, phytoseiids successfully control thrips, whiteflies and spider mites [1823]. Unlike on cucumber and pepper, phytoseiid predatory mites have difficulties building up populations on tomato crops, even in the presence prey food shown to be suitable in laboratory trials, such as the tomato russet mite (TRM) Aculops lycopersici (Tryon) (Acari: Eriophyidae) and several species of whiteflies [24-26]. The inability of Phytoseiidae to establish on tomato plants is attributed to the presence of glandular trichomes, which hamper their movement $[27,28]$. Unlike the larger phytoseiid predators, smaller mites from the family Iolinidae (superfamily Tydeoidea) are not affected by the presence of glandular trichomes and can successfully establish on tomato plants [29,30]. For example, Pronematus ubiquitus (McGregor) is a small $(<300 \mu \mathrm{m})$ omnivorous mite that feeds a variety of plant-derived food sources, such as pollen and plant sap [3,31]. This predatory mite also feeds on small prey food, such as Eriophyidae mites [32] and Tetranychidae mites [33]. Besides plant-provided food sources and prey, these mites are also known to feed on various fungi [34]. Recently, this predatory mite was found to effectively control two key problems on tomato crops: russet mites, Aculops lycopersici(Tryon) (Acari: Eriophyidae), as well as powdery mildew (Oidium neolycopersici L. Kiss) [3]. This predatory mite can be pre-established and build up large populations by supplementing tomato plants with Typha pollen [3,31].

In this study, we first compared two lines of $P$. ubiquitus, collected in Belgium and the Netherlands, with regards to their reproduction when offered Typha angustifolia pollen. Secondly, we explored the nutritional value of food sources P. ubiquitus can exploit while in a tomato crop: firstly, tomato pollen, given that tomato plants flower and thus produce pollen continuously and $P$. ubiquitus can be occasionally found inside the tomato flowers (personal observations by the authors). Secondly, conidia of powdery mildew, based on the biocontrol effect $P$. ubiquitus exhibited on powdery mildew in the study of Pijnakker et al. [3] and on previous reports of fungus-feeding by Iolinidae predatory mites [36,37]. Tomato alone and T. angustifolia pollen were used as two separate controls.

A variety of food sources has been tested to support the establishment of generalist predators in greenhouse crops [23,38], including pollen [8,40,41], frozen eggs of Ephestia kuehniella Zelle [23], Artemia sp. cysts [12,43]. Here, we explored the potential of two species of prey mites for supporting a population of $\mathrm{P}$. ubiquitus on a tomato crop, namely the dried-fruit mite Carpoglyphus lactis (L.) (Acari: Carpoglyphidae) and Tarsonemus fusarii Cooreman (Acari: Tarsonemidae). The former is a conventionally used astigmatid prey mite that can support populations of phytoseiid predatory mites on crops [43] In addition, several Tarsonemidae species were found to be suitable prey mites for phytoseiids $[48,49,50]$. Lastly, based on the outcome of the feeding experiments in the laboratory, a greenhouse trial was conducted to assess the optimal application frequency of Typha pollen for the establishment of $P$. ubiquitus on tomato plants. 


\section{Materials and Methods}

Mites and plants

Two lines of P. ubiquitus were collected in Belgium (Merelbeke) and the Netherlands (Venlo), from blackberry (Rubus sp.) and grape (Vitis sp.) plants, respectively. These lines were mass-reared in the production facilities of Biobest N.V. on a diet consisting of Typha angustifolia pollen (Nutrimite ${ }^{\mathrm{TM}}$ ). Tarsonemus fusarii was produced on Aspergillus oryzae fungus grown on rice flakes (De Halm B.V.) as described by Vangansbeke et al. [49]. A mixture of yeast flakes and bran was used to produce Carpoglyphus lactis. Both prey mite species were produced in climate chambers at $22 \pm 1^{\circ} \mathrm{C}, 80 \pm 5 \%$ relative humidity and a L16:D8 photoperiod.

Tomato plants (cv. 'Marinice') (De Ruiter Seeds, The Netherlands) were sown in trays. One week after germination, tomato seedlings were transplanted to 1-L pots with potting soil (Greenyard Horticulture, Ghent, Belgium). Plants were subsequently grown in the Greenlab research facilities of Biobest (temperatue range of $16.5-22^{\circ} \mathrm{C}$ and $70 \pm 10 \%$ relative humidity).

\section{Experiment 1: Pronematus ubiquitus strain comparison}

In the first experiment, we assessed the oviposition of the two P. ubiquitus populations, collected in Belgium and the Netherlands. Each repetition involved a single adult female $P$. ubiquitus, randomly selected from the mass-rearing units, which was then placed on a $4 \mathrm{~cm}^{2}$ tomato leaf section on top of moist cotton within a $5 \mathrm{~cm}$ petri dish arena.

These leaf discs had Typha angustifolia as a food supplement. Each female was allowed to lay eggs for four days. At this time, the total number of eggs laid by each female was counted. These arenas were kept at $23 \pm 1{ }^{\circ} \mathrm{C}, 70 \pm 10 \%$ relative humidity and a L16:D8 photoperiod. The total oviposition was analyzed using generalized linear models (GLM) with a Poisson error distribution [51]. In addition, contrasts among predators were determined with general linear hypothesis testing (function glht of the package lsmeans in R, Lenth 2016).

\section{Experiment 2 \& 3: Oviposition of P. ubiquitus on alternative foods}

In these two experiments, we performed an oviposition experiment similar to the one described above using the P. ubiquitus line collected in Belgium. For Experiment 2, the food sources offered for the mites were: clean tomato leaf, tomato leaf infected with powdery mildew, tomato leaf with tomato pollen, and tomato leaf with T. angustifolia pollen. Tomato pollen was obtained from flowers collected from tomato plants (cv. 'Marinice') (De Ruiter Seeds, The Netherlands) in the Greenlab facilities. Flowers were dried for $72 \mathrm{~h}$ at room temperature $\left(20-23^{\circ} \mathrm{C}\right)$ and relative humidity $(30-50 \% \mathrm{RH})$. Thereafter, pollen could be removed easily from the flowers before being frozen at $-18^{\circ} \mathrm{C}$. Experiment 3 had the same tomato leaf and tomato with T. angustifolia pollen treatments as the previous experiment, as well as the tomato with the prey mites T. fusarii or C. lactis. For both prey mites, a mix of all life stages was offered. The total oviposition of Experiment 2 was compared among treatments with a general linear model (GLM) with a Poisson error distribution [51]. For Experiment 3, the comparison among treatments was also done with GLM. However, the distribution for this case was a Quasi-Poisson error distribution due to the overdispersion of the data. In addition, contrasts among predators were determined with general linear hypothesis testing (function glht of the package lsmeans in $\mathrm{R}$, [52]). 
For this experiment, a cage trial was performed on individual tomato plants cv. Merlice (De Ruiter Seeds, the Netherlands) to determine the ideal frequency of application of T. angustifolia pollen to promote $P$. ubiquitus population growth. Four frequencies of pollen application were evaluated in comparison with control without pollen supplement. Five treatments were arranged in a randomized complete block design with five replicates: P. ubiquitus without pollen supplement, $P$. ubiquitus + pollen supplement weekly, $P$. ubiquitus + pollen every two weeks, $P$. ubiquitus + pollen every three weeks, $P$. ubiquitus + pollen every four weeks. Fifty $P$. ubiquitus were introduced per plant at the first week of the experiment and an additional 100 one week later. A dose of $0.1 \mathrm{~g}$ of Typha sp. pollen was added to each plant at the frequency defined for each treatment. This amount of pollen per application corresponds to the recommended amount of $500 \mathrm{~g} / \mathrm{ha}$ for supplementary feeding of phytoseiid predatory mites [40,41]. The first assessment was carried out two weeks after the first introduction of $P$. ubiquitus. Assessments involved counting the number of $P$. ubiquitus on $7 \mathrm{~cm}^{2}$ per leaflet under a stereoscopic microscope. These counts were repeated for five consecutive weeks following the second release. The number of mites was compared among treatments with a linear mixed-effects model (LME) with treatment and time as a fixed factor and plant identity as a random factor to correct for repeated measures. Non-significant interactions and factors were removed from the model. In addition, contrasts among predators were determined with general linear hypothesis testing (function glht of the package lsmeans in R, [52]). All analyses were performed using the statistical software R 3.6.1 [53].

\section{Results}

Experiment 1: Pronematus ubiquitus strain comparison

No difference was observed in the reproduction capacity of the $P$. ubiquitus collected in Belgium and the Netherland strain (Figure 1: GLM, $\chi 2=0.34 ; p=0.56$ ).

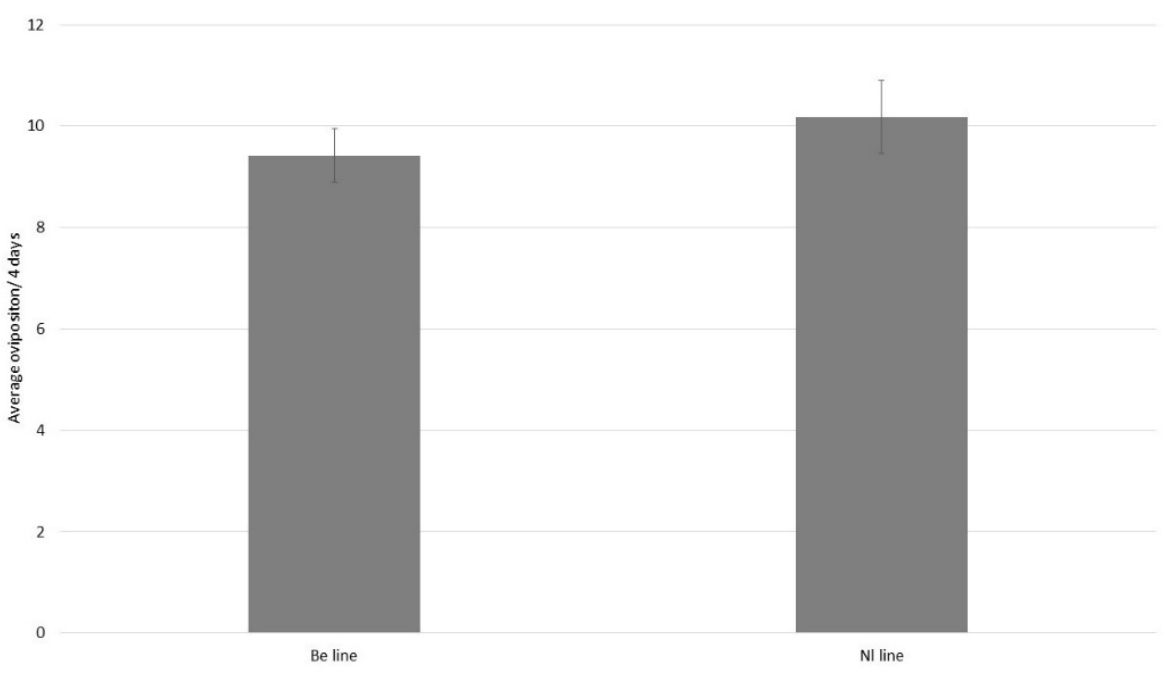

Figure 1 Average of the total oviposition for four days for P. ubiquitus either collected in Belgium (Be line) or the Netherlands ( $\mathrm{Nl}$ line) on a tomato leaf with the addition of T. angustifolia pollen. No significant differences between the two lines (GLM, $\chi 2=0.34 ; \mathrm{p}=0.56$ ).

Experiment 2: Oviposition of P. ubiquitus on naturally occurring food sources on tomato crops 
The different food sources significantly impacted the oviposition of $P$. ubiquitus (Figure 2: GLM, $\chi 2=100.8 ; \mathrm{p}<0.001)$. The highest oviposition was recorded when T. angustifolia was offered as a food source, followed by tomato pollen (Figure2). When mites had access to powdery mildew, only a marginal improvement in the oviposition was recorded (Figure 2). The lowest oviposition was observed when the tomato leaf had no additional food source (Figure 2).

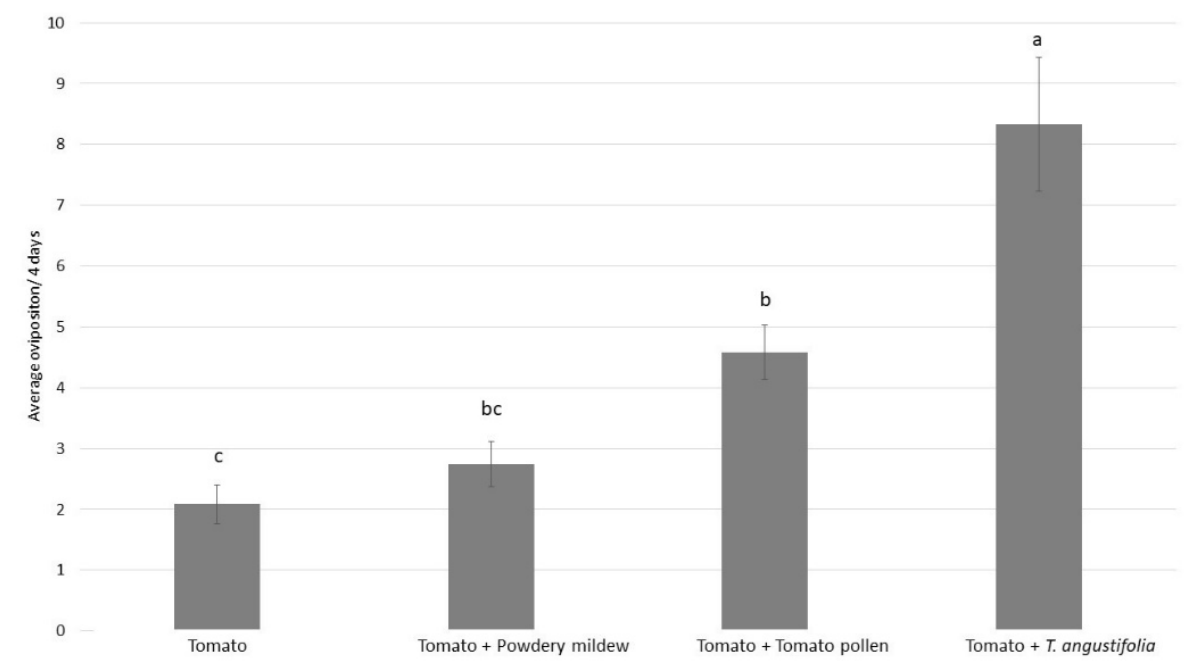

Figure 2 Average of the total oviposition over the course of 4 days for P. ubiquitus on tomato alone, tomato with powdery mildew, tomato with tomato pollen and tomato and T. angustifolia. Different letters above the bars denote significant difference among treatments (contrast after GLM, $\mathrm{p}<$ $0.05)$

The oviposition of P. ubiquitus was influenced by the different food sources (Figure 3: the highest oviposition rate, followed by the tarsonemid prey mite T. fusarii (Figure 3). The prey mite C. lactis did not show any additional effect on the reproduction of P. ubiquitus compared to the tomato leaf alone (Figure 3).

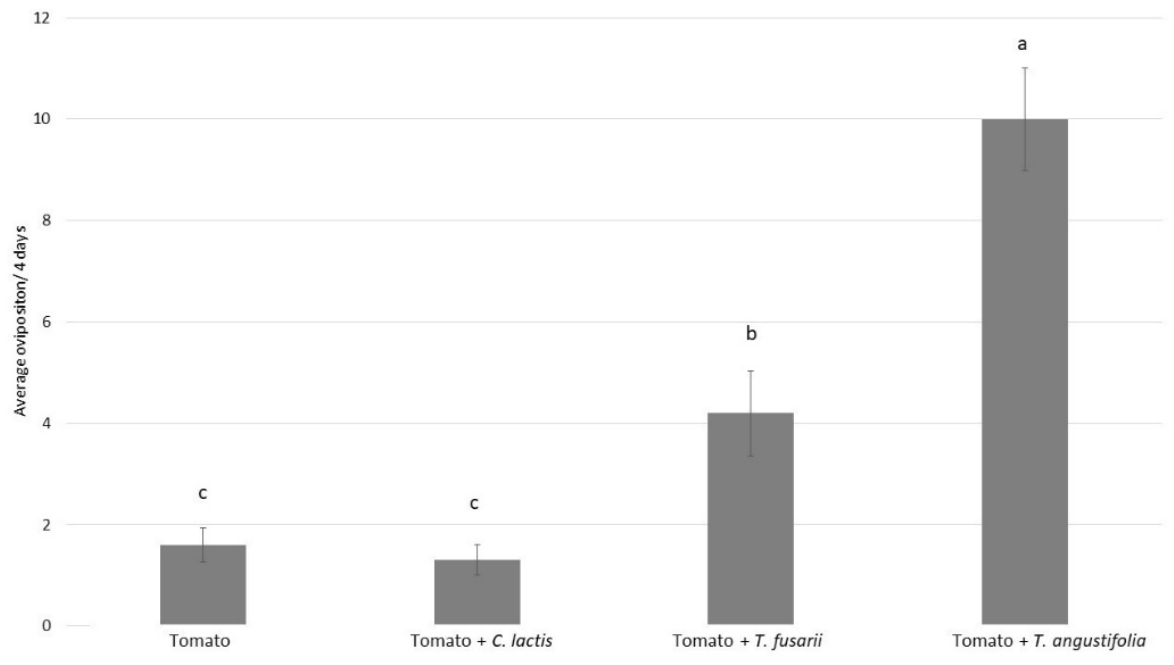

Figure 3 Average total oviposition over four days for $P$. ubiquitus on tomato alone, tomato with $C$. lactis, tomato with T. fusarii and tomato with T. angustifolia. Different letters above the bars denote significant differences among treatments (contrast after GLM, $\mathrm{p}<0.05$ ) 
There was a significant interaction between the frequency of application of T. angustifolia and time on the population of $P$. ubiquitus (Figure 4 LME, $\chi=102.9, p<0.001$ ). Weekly application of pollen resulted in the highest number of $P$. ubiquitus, followed by application every other week (Figure 4). However, the application of pollen every three or four weeks did provide an initial benefit; this benefit was not sustained during the entire trial (Figure 4).

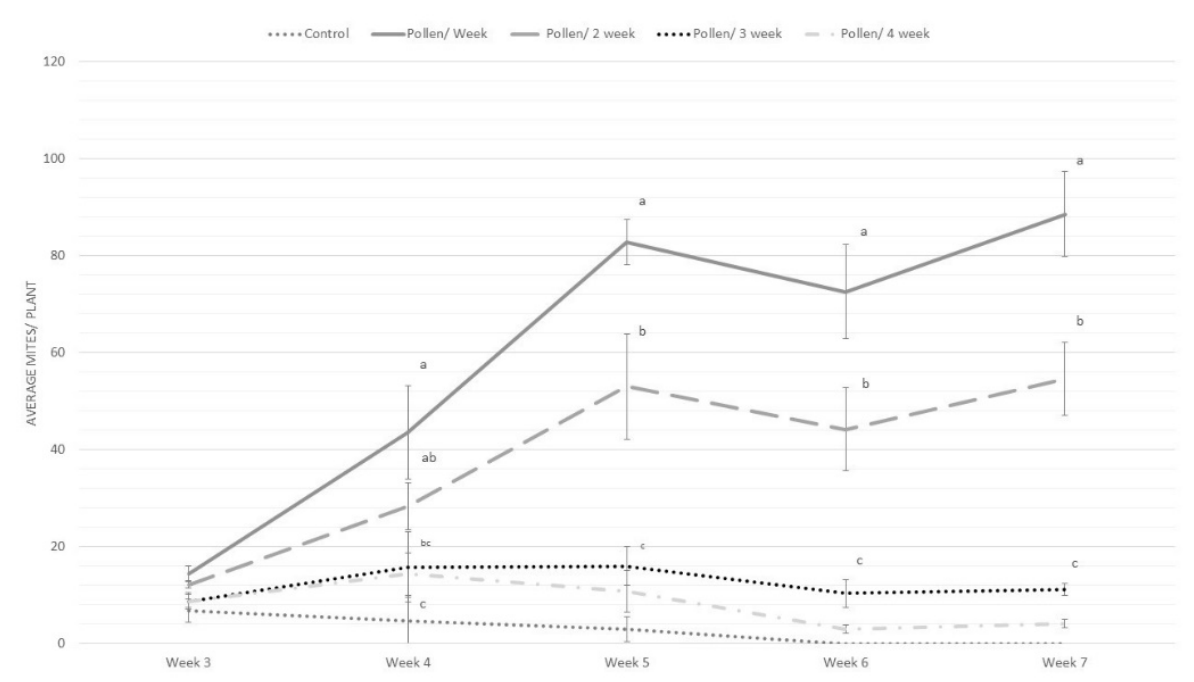

Figure 4 Population dynamics of $P$ ubiquitus when fed with a different $T$. angustifolia frequency. Control plant did not receive pollen. Pollen/ week represents pollen addition weekly, Pollen/ 2 week means pollen addition every other week, Pollen/ 3 week is for a pollen application every 3 weeks and Pollen/ 4 week is one pollen application every four weeks. Different letters above the data points denote significant differences among treatments during that week (contrast after LME, $\mathrm{p}<0.05$ )

\section{Discussion}

In this study, different natural and factitious food sources were evaluated for the predatory mite P. ubiquitus. Overall, Typha angustifolia pollen was found to be the most suitable food source for reproduction compared to a diet consisting of fungus (i.e. powdery mildew) or prey mites. These results confirm the findings of previous studies showing pollen to be an excellent food for Iolinidae predatory mites, such as P. ubiquitus and the closely related Homeopronematus anconai (Baker) (Acari: Iolinidae) [35,37]. However, tomato pollen was found to be inferior as compared to T. angustifolia pollen. Moreover, the greenhouse trial confirmed that in absence of T. angustifolia pollen, thus tomato pollen being the only food source, only a few predatory mites were observed on the tomato plants by the end of the trial period. This confirms that pollen derived from different plant species can differ greatly in their nutritional quality for predatory mites $[6,54]$.

Furthermore, other pollen features such as grain size, structure, and exine thickness determine the suitability of a pollen food source [55]. For example, anemophilous pollen is generally small and low in weight instead of bigger and heavier pollen of entomophilous plant species $[6,56]$. However, both pollen species tested here have a diameter of ca. $20 \mu \mathrm{m}[55,57]$. Therefore, size cannot explain the observed differences in reproductive output. 
Even though tomato is a self-pollinating plant, the agitation of the anthers (e.g., by pollinators or by wind) facilitates the removal of the pollen grains. As a result, tomato pollen tends to be confined in flowers and only a limited amount of pollen will drop down to the leaves below to serve as food for the mites. Tomato growers introduce bumblebee hives in the greenhouse to facilitate crop pollination. By engaging in so-called "buzzpollination", bumblebees promote the release of tomato pollen from the anthers [58], resulting in optimal fruit set and yield [59]. In this study, no bumblebees were present during the trial as plants were confined individually in cages. It remains to be investigated whether bumblebee presence would allow pollen to drop down more due to the buzz-pollination, thereby supporting populations of P. ubiquitus on the tomato crop.

Finally, pollen quality and quantity depend on the tomato cultivar [60,61], which has been shown to influence bumblebee behavior in tomato crops [62]. Likewise, the reproductive and population growth performance of $P$. ubiquitus might be affected by the tomato cultivar itself via plant feeding.

Tydeid mites are well known to engage in fungivory. For example, Orthotydeus lambi (Baker) was found to reduce the incidence and severity of grape powdery mildew, Uncinula necator (Schwein.) Burrill on both potted and field-grown vine plants [63,64]. Recently, Pijnakker et al. [3] reported the potential of $P$. ubiquitus to control powdery mildew on tomato plants. The reproductive output of $P$. ubiquitus on powdery mildew in our laboratory trial was lower than on a pollen diet and similar to the tomato leaf-only treatment. Likewise, Hessein and Perring [37] reported that the presence of the fungus Cladosporium cladosporioides (Fres.) de Vries on grape leaf arenas yielded the same low number of H. anconai as compared to a grape leaf-only treatment. In contrast, high numbers of mites were retrieved when grape leaf arenas were supplemented with Typha sp. pollen. Although feeding on powdery mildew conidia and mycelia was observed, the exact mechanisms through which $P$. ubiquitus controls powdery mildew on tomato, as reported in the study of Pijnakker et al. [3] remains to be elucidated. Being a plant feeding mite, indirect plant-mediated effects might be triggered by feeding on the plant tissue, similar to what was observed in other plant-feeding natural enemies [65]. Further study is required to investigate whether the biocontrol effect of $P$. ubiquitus on powdery mildew is due to feeding on the fungus, plant-mediated effects, or a combination thereof.

Food supplementation has become a standard practice in biocontrol programs in several crops to support the pre-establishment of generalist predators (Messelink et al. 2014; Pijnakker et al. 2021; Benson and Labbé 2021). Astigmatid prey mites are a relatively cheap alternative food source explored as a food supplement on crops, mainly to feed phytoseiid predatory mites [2]. The reproduction of P. ubiquitus on C. lactis in our study was negligible. Hence, $C$. lactis will most likely not be suitable for supporting Pronematus populations in a tomato crop. On the other hand, the tarsonemid prey mite, T. fusarii, allowed reproduction in P. ubiquitus, albeit to a lesser extent than T. angustifolia pollen. Body size is an important factor determining the outcome of prey-predator interactions $[66,67]$ and could explain why smaller tarsonemid prey mites would be more suitable than the larger C. lactis. Typha angustifolia pollen was clearly superior to the other foods tested, and although pollen would be the preferred food supplement based on our laboratory trials as well as previous results, it might nevertheless be interesting to test combinations of different food sources. Mixing two diets was reported to yield higher reproduction than offering single diets in predatory mites [68-70].

Based on the results of the laboratory trials, we tested the impact of T. angustifolia pollen application frequency on $P$. ubiquitous establishment on tomato plants. Our results 
good population build-up of P. ubiquitus. Populations could be maintained though, using less frequent applications (every three or four weeks). For the phytoseiid predatory mite Iphiseius degenerans Berlese on cucumber, van Rijn et al. [40] found that 14-day-old Typha latifolia recollected from the crop still allowed immature development and reproduction, although at a lower rate as compared to freshly applied pollen.

For phytoseiid predatory mites, differences in life history traits have occasionally been observed between different strains of the same species [71,72]. Here, we did not observe differences in egg-laying on T. angustifolia pollen between the two lines of P. ubiquitus collected from Belgium and the Netherlands. This result is to be expected since both collection sites were close and no morphological differences were observed between strains (de Vis and Ueckermann personal communication)

\section{Conclusions}

In summary, we showed that $T$. angustifolia pollen is a good food source to sustain the reproduction of $P$. ubiquitus. Application of $T$. angustifolia pollen allows the build-up of $P$. ubiquitus populations on tomato plants when applied at a frequency of at least once every two weeks at a dose rate of $500 \mathrm{~g}$ of pollen per hectare. Tomato pollen was found to support the reproduction of $P$. ubiquitus, but to a far lesser extent than Typha pollen. Finally, tarsonemid prey mites, like T. fusarii, show potential from our laboratory trials to support populations of $P$. ubiquitous, while the larger astigmatid prey mite $C$. lactis was not suitable.

Author Contributions Conceptualization: MVAD, DV, ALFS, FW; methodology: MVAD, DV, JP, $\mathrm{AB}, \mathrm{RM}$ formal analysis: MVAD, VD; writing: MVAD, VD, JP, ALFS, YA, FW; investigation: MVAD, $\mathrm{DV}$, JP, AB; supervision: FW. All authors have read and agreed to the published version of the manuscript.

\section{Institutional Review Board Statement: Not applicable.}

Data Availability Statement: The raw data are available from the corresponding author upon request.

Acknowledgments: We would like to thank, Peggy Bogaerts, and Ilse Jacobs for their technical support in greenhouse trials. We thank also Eddie Ueckermann and Raf de Vis for the identification of the mites. This work was done alongside the Flanders Agency for Innovation and Entrepreneurship VLAIO project 'BALTO'.

Conflicts of Interest: The authors declare no conflict of interest.

\section{References}

1. Symondson, W.O.C.; Sunderland, K.D.; Greenstone, M.H. Can Generalist Predators be Effective Biocontrol Agents? Annu. Rev. Entomol. 2002, 47, 561-594.

2. Messelink, G.J.; Bennison, J.; Alomar, O.; Ingegno, B.L.; Tavella, L.; Shipp, L., Palevsky, E.; Wäckers, F.L. Approaches to conserving natural enemy populations in greenhouse crops: current methods and future prospects. BioControl 2014, 59, 377393.

3. Pijnakker, J.; Moerkens, R.; Vangansbeke, D.; Duarte M.; Bellinkx S.; Benavente A.; Merckx J.; Stevens I.; Wäckers, F. Dual protection: A tydeoid mite effectively controls both a problem pest and a key pathogen in tomato." Pest Manag. Sci. 2021.

4. Messelink, G.J.; van Maanen, R.; van Steenpaal, S.E.; Janssen, A. Biological control of thrips and whiteflies by a shared predator: two pests are better than one. Biol. Control 2008, 44, 372-379.

5. Leman, A.; Ingegno, B.L.; Tavella, L.; Janssen, A.; Messelink, G.J. The omnivorous predator Macrolophus pygmaeus, a good candidate for the control of both greenhouse whitefly and poinsettia thrips on gerbera plants. Insect Sci. 2020, 27(3), 510518.

6. Goleva, I.; Zebitz, C.P.W. Suitability of different pollen as alternative food for the predatory mite Amblyseius swirskii (Acari, Phytoseiidae). Exp. Appl. Acarol. 2013, 61, 259-283.

7. Mendoza, J.E.; Balanza, V.; Cifuentes, D.; Bielza, P. Genetic improvement of Orius laevigatus for better fitness feeding on pollen. J. Pest Sci. 2021, 94(3), 729-742.

8. Leman, A.; Messelink, G.J. Supplemental food that supports both predator and pest: a risk for biological control? Exp. Appl. Acarol. 2015, 65, 511-524. 
9. Wäckers, F.L. Suitability of (extra-) floral nectar, pollen, and honeydew as insect food sources. In Plant-provided food for carnivorous insects: A protective mutualism and its applications, Cambridge University Press, Cambridge, U.K., 2005; pp. 17-74.

10. Duarte, M.V.A.; Venzon, M.; Bittencourt, M.C.D.S.; Rodriguez-Cruz, F.A.; Pallini, A.; Janssen, A. Alternative food promotes broad mite control on chilli pepper plants. Biocontrol 2015, 60, 817-825.

11. Kumar, V.; Xiao, Y.; McKenzie, C.L.; Osborne, L.S. Early establishment of the phytoseiid mite Amblyseius swirskii (Acari: Phytoseiidae) on pepper seedlings in a Predator-in-first approach. Exp. Appl. Acarol. 2015, 65, 465-481.

12. Vangansbeke, D.; Nguyen, D.T.; Audenaert, J.; Gobin, B.; Tirry, L.; De Clercq, P. Establishment of Amblyseius swirskii in greenhouse crops using food supplements. Syst. Appl. Acarol. 2016a, 21, 1174-1184.

13. McGregor, R.; Crisp, K.; Castiglia, C. Feeding lifestyles of the Phytoseiidae revisited: searching for a factitious rearing host for Neoseiulus fallacis (Acari: Phytoseiidae). BioControl 2020, 65, 593-599.

14. Calvo, F.J.; Knapp, M.; van Houten, Y.M.; Hoogerbrugge, H.; Belda, J.E. Amblyseius swirskii: what made this predatory mite such a successful biocontrol agent? Exp. Appl. Acarol. 2015, 65(4), 419-433.

15. Massaro, M.; Montrazi, M; Melo, J.W.S.; de Moraes, G.J. Small-Scale Production of Amblyseius tamatavensis with Thyreophagus cracentiseta (Acari: Phytoseiidae, Acaridae). Insects 2021, 12(10), 848.

16. Knapp, M.; van Houten, Y.; van Baal E.; Groot, T. Use of predatory mites in commercial biocontrol: current status and future prospects. Acarologia 2018, 58 (Suppl.), 72-82.

17. van Lenteren, J.C. The state of commercial augmentative biological control: plenty of natural enemies, but a frustrating lack of uptake. BioControl 2012, 57, 1-20.

18. Ramakers, P.M.J. Biological control of Thrips tabaci (Thysanoptera: Thripidae) with Amblyseius spp. (Acari: Phytoseiidae). Bulletin SROP 1980, 3, 203-207.

19. Messelink, G.J.; van Steenpaal, S.E.F.; Ramakers, P.M.J. Evaluation of phytoseiid predators for control of western flower thrips on greenhouse cucumber. BioControl 2006, 51, 753-768.

20. Palevsky, E.; Walzer, A.; Gal, S.; Schausberger, P. Evaluation of dry-adapted strains of the predatory mite Neoseiulus californicus for spider mite control on cucumber, strawberry and pepper. Exp. Appl. Acarol. 2008, 45(1), 15-27.

21. Calvo, F.J.; Bolckmans, K.; Belda, J.E. Control of Bemisia tabaci and Frankliniella occidentalis in cucumber by Amblyseius swirskii. BioControl 2011, 56(2), 185-192.

22. Calvo, F.J.; Bolckmans, K.; Belda, J.E. Biological control-based IPM in sweet pepper greenhouses using Amblyseius swirskii (Acari: Phytoseiidae). Biocontrol Sci. Technol. 2012, 22(12), 1398-1416.

23. Labbé, R.M.; Gagnier, D.; Shipp, L. Comparison of Transeius montdorensis Acari: Phytoseiidae) to other phytoseiid mites for the short-season suppression of western flower thrips, Frankliniella occidentalis (Thysanoptera: Thripidae). Environ. entomol. 2019, 48(2), 335-342.

24. Park, H.-H.; Shipp, L.; Buitenhuis R.; Ahn J.J. Life history parameters of a commercially available Amblyseius swirskii (Acari: Phytoseiidae) fed on cattail (Typha latifolia) pollen and tomato russet mite (Aculops lycopersici). J. Asia-Pac. Entomol. 2011, 14, 497-501.

25. Paspati, A.; Rambla, J.L.; Gresa, M.P.L.; Arbona, V.; Gómez-Cadenas, A.; Granell, A.; González-Cabrera, J.; Urbaneja, A. Tomato trichomes are deadly hurdles limiting the establishment of Amblyseius swirskii Athias-Henriot (Acari: Phytoseiidae). Biological Control 2021, 157, 104572.

26. Vervaet L.; De Vis R.; de Clercq P.; van Leeuwen, T. Is the emerging mite pest Aculops lycopersici controllable? Global and genome-based insights in its biology and management. Pest Manag. Sci. 2021.

27. Drukker, B.; Janssen, A.; Ravensberg, W., Sabelis, M.W. Improved control capacity of the mite predator Phytoseiulus persimilis (Acari: Phytoseiidae) on tomato. Exp. Appl. Acarol. 1997, 21, 507-518.

28. Van Haren, R.J.; Steenhuis, M.M.; Sabelis, M.W.; De Ponti, O.D. Tomato stem trichomes and dispersal success of Phytoseiulus persimilis relative to its prey Tetranychus urticae. Exp. Appl. Acarol. 1987, 3(2), 115-21.

29. Kawai, A.; Haque, M.M. Population dynamics of tomato russet mite, Aculops lycopersici (Massee) and its natural enemy, Homeopronematus anconai (Baker). Jarq-Jpn. Agr. Res. Q. 2004, 38, 161-166.

30. Aysan, E.; Kumral, N.A. Tritrophic relationships among tomato cultivars, the rust mite, Aculops lycopersici (Massee) (Eriophyidae), and its predators. Acarologia 2018, 58, 5-17. doi: 10.24349/acarologia/20184283

31. Van Houten, Y.M.; Hoogerbrugge, H.; Knapp, M. Potential of Pronematus ubiquitus to control tomato russet mite, Aculops lycopersici. IOBC/WPRS Bull. 2020, 149, 87-92.

32. Baradaran, P.; Arbabi, M. Population abundance of Pronematus ubiquitus (McGregor, 1932) (Acari: Tydeidae) on different fig varieties. J. Entomol. Res. 2009, 1(2), 177-183.

33. Dean, H.A. Predators of Oligonychus pratensis (Banks), Tetranychidae. Ann. Entomol. Soc. Am. 1957, 50(2), $164-165$.

34. McCoy, C.W.; Selhime, A.G.; Kanavel, R.F. The Feeding Behavior and Biology of Parapronematus acaciae (Acarina: Tydeidae). Fla. Entomol. 1969, 52, 13.

35. Knop, N.F.; Hoy, M.A. Biology of a tydeid mite, Homeopronematus anconai (n. comb.) (Acari: Tydeidae), important in San Joaquin valley vineyards. Hilgardia 1983a, 51, 1-30.

36. Knop, N.F.; Hoy, M.A. Factors Limiting the Utility of Homeopronematus anconai (Acari: Tydeidae) in Integrated Pest Management in San Joaquin Valley Vineyards. J. Econ. Entomol. 1983 b, 76, 1181-1186. 
37. Hessein, N.A.; Perring, T.M. The importance of alternate foods for the mite Homeopronematus anconai (Acari: Tydeidae). Ann. Entomol. Soc. Am. 1988, 81 (3), 488-492.

38. Pijnakker. J.; Vangansbeke, D.; Duarte, M.; Moerkens, R.; Wäckers, F.L. Predators and Parasitoids-in-First: From Inundative Releases to Preventative Biological Control in Greenhouse Crops. Front. Sustain Food Syst. 2020, 4, 245.

39. Benson, C.M.; Labbe, R.M. Exploring the Role of Supplemental Foods for Improved Greenhouse Biological Control. Ann. Entomol. Soc. Am. 2021, 114(3), 302-321.

40. van Rijn, P.C.J.; van Houten, Y.M.; Sabelis, M.W. How plants benefit from providing food to predators even when it is also edible to herbivores. Ecology 2002, 83, 2664-2679.

41. Pijnakker, J.; Arijs, Y.; de Souza, A.; Cellier, M.; Wäckers, F. The use of Typha angustifolia (cattail) pollen to establish the predatory mites Amblyseius swirskii, Iphiseius degenerans, Euseius ovalis and Euseius gallicus in glasshouse crops, Integrated Control of Plant-FeedingMites. IOBC/WPRS Bull. 2016, 120, 47-52.

42. Labbé, R.M.; Gagnier, D.; Kostic, A.; Shipp, L. The function of supplemental foods for improved crop establishment of generalist predators Orius insidiosus and Dicyphus hesperus. Sci. Rep. 2018, 8, 17790.

43. Brenard, N.; Sluydts, V.; Christianen, E.; Bosmans, L.; De Bruyn, L.; Moerkens, R.; Liers, H. Biweekly supplementation with Artemia spp. cysts allows efficient population establishment by Macrolophus pygmaeus in sweet pepper. Entomol. Exp. Appl. 2019, 167, 406-414.

44. Hoogerbrugge, H.; van Houten, Y.; van Baal, E.; Bolckmans, K. Alternative food sources to enable establishment of Amblyseius swirskii (Athias-Henriot) on chrysanthemum without pest presence. IOBC/WPRS Bull. 2008, 32, 79.

45. Pirayeshfar, F.; Safavi, S.A.; Sarraf Moayeri, H.R.; Messelink, G.J. The potential of highly nutritious frozen stages of Tyrophagus putrescentiae as a supplemental food source for the predatory mite Amblyseius swirskii. Biocontrol Sci. Technol. 2020, 30(5), 403-417.

46. Pirayeshfar, F.; Safavi, S.A.; Moayeri, H.R.S.; Messelink, G.J. Provision of astigmatid mites as supplementary food increases the density of the predatory mite Amblyseius swirskii in greenhouse crops, but does not support the omnivorous pest, western flower thrips. BioControl 2021, 1-12.

47. Muñoz-Cárdenas, K.; Ersin, F.; Pijnakker, J.; van Houten, Y.; Hoogerbrugge, H.; Leman, A.; ...; Janssen, A. Supplying highquality alternative prey in the litter increases control of an above-ground plant pest by a generalist predator. Biological control 2017, 105, 19-26.

48. Li, L.; Jiao, R.; Yu, L.; He, X.Z.; He, L.; Xu, C.; Zhang, L.; Liu, J. Functional response and prey stage preference of Neoseiulus barkeri on Tarsonemus confusus. System. Appl. Acarol. 2018, 23(11), 2244-2258.

49. Vangansbeke, D.; Duarte, M.V.; Merckx, J.; Benavente, A.; Magowski, W.L.; França, S.C.; ...; Wäckers, F.L. Impact of a tarsonemid prey mite and its fungal diet on the reproductive performance of a predatory mite. Exp. Appl. Acarol. 2021, 83(3), 313-323.

50. Farfan, M.A.; Coffey, J.; Schmidt-Jeffris, R.A. Evaluation of Tarsonemus bilobatus and Podosphaera xanthii as suitable resources for Proprioseiopsis mexicanus in cucurbit systems in the Southeast USA. Exp. Appl. Acarol. 2021, 85(1), 31-40.

51. Crawley, M.J. The R book. John Wiley \& sons, Ltd, Chichester, West Sussex, U.K., 2007; pp. 950.

52. Lenth, R. Least-Squares Means: The R Package lsmeans. J. Stat. Softw. 2016, 69(1), 1-33.

53. Core Team R. R: A language and environment for statistical computing, R Foundation for Statistical Computing, Vienna, Austria, 2018.

54. Samaras, K.; Pappas, M.L.; Fytas, E.; Broufas, G.D. Pollen suitability for the development and reproduction of Amblydromalus limonicus (Acari: Phytoseiidae). Biocontrol 2015, 60, 773-782.

55. van Rijn, P.C.J.; Tanigoshi, L.K. Pollen as food for the predatory mites Iphiseius degenerans and Neoseiulus cucumeris (Acari: Phytoseiidae): dietary range and life history. Exp. Appl. Acarol. 1999a, 23, 785-802.

56. Stanley, R.G.; Linskens, H.F. Pollen. Biology Biochemistry Management. Springer, Verslag New York, Heidelberg, Berlin, 1974; pp. 289.

57. Bohs, L.. Transfer of Cyphomandra (Solanaceae) and its species to Solanum. Taxon. 1995, 583-587.

58. Buchmann, S.L.; Hurley, J.P. A biophysical model for buzz pollination in angiosperms. J. Theor. Biol. 1978, 72(4), $639-657$.

59. van Ravestijn, W.; Van der Sande, J. Use of bumblebees for the pollination of glasshouse tomatoes. In VI International Symposium on Pollination (1990, August), ISHS Acta Hortic. 1991, 288, $204-212$.

60. Poulton, J.L.; Koide, R.T.; Stephenson, A.G. Effects of mycorrhizal infection and soil phosphorus availability on in vitro and in vivo pollen performance in Lycopersicon esculentum (Solanaceae). Am. J. Bot. 2001, 88(10), 1786-1793.

61. Firon, N.; Shaked, R.; Peet, M.M.; Pharr, D.M.; Zamski, E.; Rosenfeld, K.; ...; Pressman, E. Pollen grains of heat tolerant tomato cultivars retain higher carbohydrate concentration under heat stress conditions. Sci. Hortic. 2006, 109 (3), $212-217$.

62. Lefebvre, D.; Pierre, J. Hive weight as an indicator of bumblebee colony growth. J. Apicult. Res. 2006, 45(4), 217-218.

63. English-Loeb, G.; Norton, A.P.; Gadoury, D.M.; Seem R.C.; Wilcox, W.F. Control of Powdery Mildew in Wild and Cultivated Grapes by a Tydeid Mite. Biol. Control 1999, 14, 97-103.

64. English-Loeb, G.; Norton, A.P.; Gadoury, D.; Seem, R.; Wilcox, W. (2007). Biological control of grape powdery mildew using mycophagous mites. Plant Dis. 2007, 91(4), 421-429.

65. Pappas, M.L.; Steppuhn, A.; Broufas, G.D. The role of phytophagy by predators in shaping plant interactions with their pests. Commun. Integr. Biol. 2016, 9:e0127251. 
66. Travis, J.; Keen, W.H.; Juilianna, J. The role of relative body size in a predator-prey relationship between dragonfly naiads and larval anurans. Oikos 1985, 59-65.

67. Emmerson, M.C.; Raffaelli, D. Predator-prey body size, interaction strength and the stability of a real food web. J. Anim. Ecol. 2004, 73(3), 399-409.

68. Pappas, M.L.; Xanthis, C.; Samaras, K.; Koveos, D.S.; Broufas, G.D. Potential of the predatory mite Phytoseius finitimus (Acari: Phytoseiidae) to feed and reproduce on greenhouse pests. Exp. Appl. Acarol. 2013 61(4), 387-401.

69. Samaras, K.; Pappas, M.L.; Pekas, A.; Wäckers, F.; Broufas, G.D. Benefits of a balanced diet? Mixing prey with pollen is advantageous for the phytoseiid predator Amblydromalus limonicus. Biol. Control 2021, 155, 104531.

70. Asgari, F.; Moayeri, H.R.S.; Kavousi, A.; Enkegaard, A.; Chi, H. Demography and mass rearing of Amblyseius swirskii (Acari: Phytoseiidae) fed on two species of stored-product mites and their mixture. J. Econ. Entomol. 2020, 113(6), $2604-2612$.

71. Castagnoli, M.; Simoni, S.; Nachman, G. Short-term changes in consumption and oviposition rates of Neoseiulus californicus strains (Acari: Phytoseiidae) after a diet shift. Exp. Appl. Acarol. 2001, 25(12), 969-983.

72. Perring, T.M.; Lackey, L.J. Temperature and humidity effects on mortality and pre-adult development of two Phytoseiulus persimilis strains (Acari: Phytoseiidae). Int. J. Acarol. 1989, 15(1), 47-52. 